\title{
Prevalence and control of hypertension among a Community of Elderly Population in Changning District of shanghai: a cross- sectional study
}

\author{
Zhi-Qi Yang ${ }^{1}$, Qi Zhao ${ }^{1,2}$, Ping Jiang ${ }^{3}$, Song-Bai Zheng ${ }^{4}$ and Biao Xu ${ }^{1,2,5,6^{*}}$ (D)
}

\begin{abstract}
s
Background: Hypertension is considered a major public health challenge. It is the most important risk factor for cardiovascular disease and is a prominent risk for China's elderly population. However, few studies have addressed the effect of blood pressure control on elderly hypertension patients in China. In response, this study aimed to investigate the prevalence and control of hypertension in the elderly population in Shanghai's communities.

Methods: A secondary data analysis based on a government-financed health check-up program for an elderly population aged 65 and older from 2012 to 2014 was conducted in a central district of Shanghai.

Results: Of the 44,978 study participants, 20,305 (45.1\%) were males and 24,673 (54.9\%) were females. The participants' median age was 72. Half of the participants were overweight or obese (BMI $\left.\geq 24.0 \mathrm{~kg} / \mathrm{m}^{2}\right)$. The prevalence of hypertension was $59.9 \%$. In the 18,032 participants without prior diagnosis of hypertension, 5530 (30.7\%) had increased blood pressure. Among the 26,946 confirmed hypertension patients, the proportions of treatment and blood pressure control were $32.8 \%$ and $43.4 \%$ respectively. Multivariate analysis showed that the uncontrolled hypertension was significantly associated with older age, being overweight or obese, a lower level of education, an unbalanced dietary pattern, regular drinking and non-comorbidities.

Conclusions: The prevalence of hypertension was high in China's elderly population. The proportion of individuals who received treatment remained low, and blood pressure control was poor among hypertension patients. These results indicate that improvement of the ability to manage and control hypertension among urban elderly residents is urgently needed.
\end{abstract}

Keywords: Elderly population, Hypertension, Prevalence, Blood pressure control

\section{Background}

Globally, cardiovascular disease (CVD) became the leading cause of mortality in 2013 and was responsible for nearly one-third of all deaths [1]. In the meantime, hypertension, which is considered to be the most crucial risk factor for CVD, has caused half of cardiovascular mortality and morbidity and led to 9.4 million deaths per year [2]. Additionally, approximately $40 \%$ of adults

\footnotetext{
* Correspondence: bxu@shmu.edu.cn

${ }^{1}$ School of Public Health, Fudan University, Shanghai, China

${ }^{2}$ Key Laboratory of Public Health Safety (Fudan University), Ministry of

Education, Shanghai, China

Full list of author information is available at the end of the article
}

who were 25 and above were diagnosed with hypertension around the world [2]. Hypertension also places a severe burden on China's population.

According to the baseline survey from the nationwide China Health and Retirement Longitudinal Study (CHARLS), hypertension had a higher under-diagnosis rate among middle-aged and elderly Chinese [3]. The prevalence of hypertension among study respondents over 75 years was $58.0 \%$ for men and $62.1 \%$ for women [3]. Although hypertension has been considered a treatable condition, lifelong intake of medication is required to control a patient's blood pressure. In many regions of the world, especially in 
low and middle-income countries such as China, hypertension control remains a major health threat [4-6].

Population aging presents a tremendous challenge for China's hypertension control. The United Nations estimated that individuals aged $\geq 60$ constituted $16.2 \%$ of the total Chinese population in 2017, and they predicted the percentage would increase to $35.1 \%$ by 2050 [7]. As a large metropolitan city in China, the ageing population in Shanghai is increasingly serious, especially in central districts. Elderly people are at a higher risk of non-communicable diseases, hypertension and raised blood pressure (BP) [8]. In Shanghai, the prevalence of hypertension was $41.9 \%$ among individuals who were $34-74$ years of age in the community population [9], and the prevalence was $59.4 \%$ among those aged $\geq 60$ years [10]. Therefore, urgent action, optimal treatment approaches and proper public health strategies are needed to prevent and manage hypertension in the elderly population.

Despite the high prevalence of hypertension in China, there is a lack of updated epidemiological evidence for BP control among the elderly population, especially in cities suffering population ageing like Shanghai. Previous studies may also have defective small sample sizes, a failure to investigate the susceptible population, or an inability to examine hypertension controls [5, 11-15].

This cross-sectional study was conducted to look into the current situation of hypertension burden in elderly Chinese residents. The study was designed to investigate the BP distribution and treatment effect among both prevalent cases and new cases with abnormal BP. The study's objectives included the following: first, to investigate the prevalence of hypertension among the community population of individuals who are 65 years and older in the Changning District, Shanghai. Second, to evaluate the effect of blood pressure control among elderly hypertension patients. Third, to explore the risk factors associated with suboptimal BP control.

\section{Methods}

\section{Study participants and data source}

This study was a secondary data analysis carried out in the Changning District, which is one of the central districts in Shanghai. The total coverage of the Changning District is $37.19 \mathrm{~km}^{2}$, including nine communities and one town. The Changning District has one of the highest proportion of elderly population in Shanghai. Among the district's 590,000 permanent residents, $20.4 \%$ were 65 years or older with a life expectancy of 84 years in 2015 [16]. Data were obtained from a governmentfinanced health information platform. The data included health archives, health check-up records and disease registrations with a solid information security system. After the approval of the research plan on elderly health, corresponding data were exported from the system without identification information. The study was based on the "Healthy Ageing" program. This program was conducted as part of the twelfth five-year plan (from 2011 to 2015) and ageing-related undertakings in Shanghai, China. The study was jointly conducted by the district Committee on Ageing and district Health \& Family Planning Commission. Since 2012, the Healthy Ageing Program has provided health check-ups free of charge for elderly residents (aged 65 and older) living in the district to further implement health management among the elderly population. For this study, we extracted health check-up data and demographic information of all the elderly residents who received this free physical check-up during 2012-2014 from the District Health Information Center. A total of 44,978 subjects were included in the study population.

\section{Data collection}

Information on social demographics, lifestyle, dietary habits, diseases and medication history were routinely recorded by trained health staff upon registration for the health check-up. Shanghai Municipal Center for Disease Control and Prevention started providing special spoons for residents to quantify salt intake in 2008. Drinking status was classified into three groups based on the frequency of alcohol consumption: never (never drinking), occasional (< once/week), regular ( $\geq$ once/week).

Blood pressure was measured using a calibrated electronic sphygmomanometer (Omron Corporation, HBP1300, Kyoto, Japan). Participants were required to rest for at least $5 \mathrm{~min}$ before BP measurements. The left upper arm BP was measured 3 times in a sitting position with guidance from trained physicians. Measurements were considered to be unstable if the differences between the last two readings exceeded $5 \mathrm{mmHg}$ and additional measurements were taken until the differences were lower than $5 \mathrm{mmHg}$. Systolic blood pressure (SBP) and diastolic blood pressure (DBP) were calculated as the averages of the last two readings of the three measurements.

\section{Definitions}

Blood pressure was used to classify individuals into six groups: normal (SBP $<120 \mathrm{mmHg}$ and $\mathrm{DBP}<80 \mathrm{mmHg}$ ), prehypertension (SBP: $120-139 \mathrm{mmHg}$ or DBP: $80-$ $89 \mathrm{mmHg}$ ), stage one hypertension (SBP: $140-159 \mathrm{mmHg}$ or DBP: $90-99 \mathrm{mmHg}$ ), stage two hypertension (SBP: 160-179 mmHg or DBP: $100-109 \mathrm{mmHg}$ ), stage three hypertension (SBP $\geq 180 \mathrm{mmHg}$ or $\mathrm{DBP} \geq 110 \mathrm{mmHg}$ ), and isolated systolic hypertension ( $\mathrm{SBP} \geq 140 \mathrm{mmHg}$ and $\mathrm{DBP}<90 \mathrm{mmHg}$ ). If any different classification of SBP and DBP seems applicable for the same person, the higher level shall prevail.

In this study, hypertension was defined as selfreported confirmed diagnosis of hypertension (medical certificates were checked by qualified physicians) and/or 
regular use of antihypertensive medication. The proportion of treatment was defined as the percentage of those who had taken antihypertensive medication, whereas the proportion of blood pressure control was defined as the percentage of individuals whose SBP and DBP were both lower than 140/90 mmHg among all the confirmed hypertension patients. The detection rate of raised blood pressure represented the proportion of participants who had $\mathrm{SBP} \geq 140 \mathrm{mmHg}$ or $\mathrm{DBP} \geq 90 \mathrm{mmHg}$ among individuals without a prior diagnosis of hypertension or use of antihypertensive medication. Comorbidity was defined as having hypertension and one or more co-existing conditions of these three non-communicable diseases (NCDs): diabetes, coronary heart disease (CHD), and stroke.

\section{Statistical analysis}

A chi-square test and one-way ANOVA (for homoscedasticity) or Mann-Whitney U test (for heteroscedasticity) were used to examine differences in the categorical and continuous variables, respectively. Multivariate analysis through binary logistic regression was applied to search factors associated with uncontrolled BP. Age, gender, body mass index (BMI), education level, dietary pattern, salt intake, treatment for hypertension, and comorbidity of other NCDs were included as covariates. All statistical analyses were performed using SPSS software (version 19.0, Chicago, Illinois, USA). A two-sided $p$ value $<0.05$ was considered statistically significant.

\section{Ethical considerations}

This routine, record-based secondary data analysis was approved by the Ethic Committee in Huadong Hospital Affiliated to Fudan University (No. 2014 K004). Informed consent was exempt because there was no individual identification information in the analytical database. A unique code was given to each participant for individual differentiation. The government financed physical check-up was offered free of charge, and participation was voluntary. Data used in the analysis were secured and exported by information technology professionals in the district information center corresponding to the research plan.

\section{Results}

\section{Demographic characteristics of participants}

A total of 44,978 people aged 65 and older (age range: 65-112 years) took the health check-up provided by the "Healthy Ageing" program from 2012 to 2014. The median age of participants was 72 (interquartile range: 6778 years), and $19.3 \%(8682 / 44,978)$ of them were 80 years or older. Participants who were 65-79 years old and over 80 years old accounted for $45.3 \%(36,296 / 80,100)$ and $23.2 \%(8682 / 37,400)$ of the whole population of their respective age groups in the district [16]. Overall, $45.1 \%(20,305 / 44978)$ of the participants were male and
$50.1 \%(22,136 / 44,151)$ were overweight or obese. Additionally, $19.5 \%$ (8771/44,978), $18.0 \%$ (8112/44,978), and $7.1 \%(3178 / 44,978)$ of the participants reported a history of diabetes, coronary heart disease and stroke, respectively. Only $8.4 \%(3713 / 44,157)$ of the participants had no formal education, whereas $15.0 \%(6621 / 44,157)$ had a college degree or higher (Table 1).

\section{Distribution of blood pressure}

In Fig. 1, the mean SBP displayed an increasing trend with age for both sexes, and females had higher SBP than males at ages of 70 or older $(p<0.001)$. Meanwhile, an inverse association was observed between DBP and age. Mean levels of DBP were similar for males and females in the 75-yearold age group $(p=0.503)$; however, males had significantly higher DBP than females in age groups below 75 years $(p<$ 0.001 ), whereas the females had a higher DBP in age groups over 75 years that was not significant $(p=0.130)$.

\section{Prevalence of hypertension and detection rate of raised blood pressure}

Overall, $59.9 \%$ of participants $(58.8 \%$ of males vs. $60.8 \%$ of females; $p<0.001$ ) had hypertension. The prevalence increased significantly according to age (65-69: 52.9\%, 70-74: 61.0\%, 75-79: 65.6\%, 80-84: 66.7\%, 85-: 65.0\%; $p$ value for the liner trend test: $<0.001)$. The prevalence of hypertensiondiabetes, hypertension-CHD, and hypertension-stroke comorbidity was $15.2 \%, 13.7 \%$ and $5.4 \%$, respectively.

Of the 18,032 participants who did not report a prior hypertension diagnosis or prior use of antihypertensive medication, 5530 (30.7\%) were detected with raised blood pressure at SBP $\geq 140 \mathrm{mmHg}$ or DBP $\geq 90 \mathrm{mmHg}$.

Based on the measured blood pressure, the proportions of participants with stage 1, 2, 3 and isolated systolic hypertension were $31.9 \%, 11.3 \%, 3.0 \%$ and $26.8 \%$, respectively. In the meantime, only $11.8 \%$ of the participants were normotensive (Table 2).

\section{Hypertension treatment and hypertension control}

Among all hypertension patients, only 32.8\% (8829/ $26,946)$ were being treated. The treatment proportion was always below $35.0 \%$ in all blood pressure grades. This proportion did not vary substantially by $\operatorname{sex}(p=$ 0.416). Among individuals who received treatment for hypertension, 43.1\% (3802/8829) achieved control of hypertension, and their average SBP and DBP were both lower than 140/90 $\mathrm{mmHg}$. The proportion of hypertension control among all confirmed hypertension patients was $43.4 \%(11,705 / 26,946)$. The proportion of BP control was $59.4 \%(16,001 / 26,946)$ with the reference set as less than $150 / 90 \mathrm{mmHg}$ according to the Eighth Joint National Committee (JNC-8) guidelines [17]. Only 6.2\% $(1660 / 26,946)$ of the hypertension patients had both SBP and DBP lower than 120/80 mmHg (Fig. 2). 
Table 1 Demographic characteristics of participants

\begin{tabular}{|c|c|c|c|c|c|c|c|c|}
\hline \multicolumn{2}{|c|}{ Demographic characteristics } & \multirow{2}{*}{\multicolumn{2}{|c|}{$\begin{array}{l}\text { Total } \\
(N=44,978)\end{array}$}} & \multirow{2}{*}{\multicolumn{2}{|c|}{$\begin{array}{l}\text { Hypertension } \\
(N=26,946)\end{array}$}} & \multirow{2}{*}{\multicolumn{2}{|c|}{$\begin{array}{l}\text { No confirmed hypertension } \\
(N=18,032)\end{array}$}} & \multirow{4}{*}{$\begin{array}{c}p \text { value }^{*} \\
<0.001\end{array}$} \\
\hline & & & & & & & & \\
\hline & & \multirow{2}{*}{$\begin{array}{l}n \\
17,348\end{array}$} & \multirow{2}{*}{$\begin{array}{l}\% \\
38.6\end{array}$} & \multirow{2}{*}{$\frac{n}{9183}$} & \multirow{2}{*}{$\begin{array}{l}\% \\
34.1\end{array}$} & \multirow{2}{*}{$\begin{array}{l}n \\
8165\end{array}$} & \multirow{2}{*}{$\begin{array}{l}\% \\
45.3\end{array}$} & \\
\hline Age (Years) & $65-$ & & & & & & & \\
\hline & $70-$ & 9105 & 20.2 & 5557 & 20.6 & 3548 & 19.7 & \\
\hline & $75-$ & 9843 & 21.9 & 6456 & 24 & 3387 & 18.8 & \\
\hline & $80-$ & 6347 & 14.1 & 4233 & 15.7 & 2114 & 11.7 & \\
\hline & $85-$ & 2335 & 5.2 & 1517 & 5.6 & 818 & 4.5 & \\
\hline \multirow[t]{2}{*}{ Gender } & Male & 20,305 & 45.1 & 11,936 & 44.3 & 8369 & 46.4 & $<0.001$ \\
\hline & Female & 24,673 & 54.9 & 15,010 & 55.7 & 9663 & 53.6 & \\
\hline \multirow[t]{4}{*}{ BMI $\left(\mathrm{kg} / \mathrm{m}^{2}\right)$} & $0-$ & 20,190 & 45.7 & 10,776 & 40.7 & 9414 & 53.2 & $<0.001$ \\
\hline & $18.5-$ & 1825 & 4.1 & 726 & 2.7 & 1099 & 6.2 & \\
\hline & $24.0-$ & 16,688 & 37.8 & 10,864 & 41.1 & 5824 & 32.9 & \\
\hline & $28.0-$ & 5448 & 12.3 & 4080 & 15.4 & 1368 & 7.7 & \\
\hline \multirow[t]{5}{*}{ Education } & University & 6621 & 15 & 3699 & 13.9 & 2922 & 16.6 & $<0.001$ \\
\hline & Senior high school & 11,074 & 25.1 & 6349 & 23.9 & 4725 & 26.8 & \\
\hline & Junior high school & 14,704 & 33.3 & 8794 & 33.2 & 5910 & 33.5 & \\
\hline & Primary school & 8045 & 18.2 & 5242 & 19.8 & 2803 & 15.9 & \\
\hline & No formal education & 3713 & 8.4 & 2443 & 9.2 & 1270 & 7.2 & \\
\hline \multirow[t]{3}{*}{ Dietary habit } & Balanced & 37,969 & 84.4 & 22,559 & 83.7 & 15,410 & 85.5 & $<0.001$ \\
\hline & Meatarian & 1645 & 3.7 & 1015 & 3.8 & 630 & 3.5 & \\
\hline & Vegetarian & 5364 & 11.9 & 3372 & 12.5 & 1992 & 11 & \\
\hline \multirow[t]{2}{*}{ Salt intake } & $\leq 6 \mathrm{mg} / \mathrm{day}$ & 43,766 & 97.3 & 26,157 & 97.1 & 17,609 & 97.7 & $<0.001$ \\
\hline & $>6 \mathrm{mg} / \mathrm{day}$ & 1212 & 2.7 & 789 & 2.9 & 423 & 2.3 & \\
\hline \multirow[t]{3}{*}{ Drinking } & Never & 29,121 & 70.8 & 17,838 & 72 & 11,283 & 69 & $<0.001$ \\
\hline & Occasional & 8299 & 20.2 & 4806 & 19.4 & 3493 & 21.4 & \\
\hline & Regular & 3685 & 9 & 2118 & 8.6 & 1567 & 9.6 & \\
\hline \multirow[t]{2}{*}{ Diabetes } & No & 36,207 & 80.5 & 20,090 & 74.6 & 16,117 & 89.4 & $<0.001$ \\
\hline & Yas & 8771 & 19.5 & 6856 & 25.4 & 1915 & 10.6 & \\
\hline \multirow[t]{2}{*}{ CHD } & No & 36,866 & 82 & 20,790 & 77.2 & 16,076 & 89.2 & $<0.001$ \\
\hline & Yas & 8112 & 18 & 6156 & 22.8 & 1956 & 10.8 & \\
\hline \multirow[t]{2}{*}{ Stroke } & No & 41,800 & 92.9 & 24,538 & 91.1 & 17,262 & 95.7 & $<0.001$ \\
\hline & Yas & 3178 & 7.1 & 2408 & 8.9 & 770 & 4.3 & \\
\hline
\end{tabular}

${ }^{*} P$ values represented the comparisons between hypertension and not confirmed hypertension from chi-square tests

\section{Factors associated with uncontrolled BP among hypertension patients}

Unsatisfactory BP control was significantly associated with an increase in age. Additionally, the percentage of uncontrolled hypertension was slightly higher among females compared to males without statistical significance. Uncontrolled blood pressure was more common among individuals with a lower education level and a larger BMI. The dietary pattern and drinking frequency had a significant association with BP control, whereas salt intake did not. Hypertension patients who present comorbidity with other NCDs (diabetes, CHD and stroke) had a higher proportion of BP control than the ones without NCD comorbidity (Table 3 ).

\section{Discussion}

To the best of our knowledge, this study was one of the largest studies in China seeking to discover the prevalence and control hypertension among the elderly population. Overall, $38.3 \%(44,978 / 117,500)$ in the base population in Changning district were enrolled. This study provided new evidence signifying the current burden of hypertension and the critical situation for uncontrolled hypertension among the elderly population in 


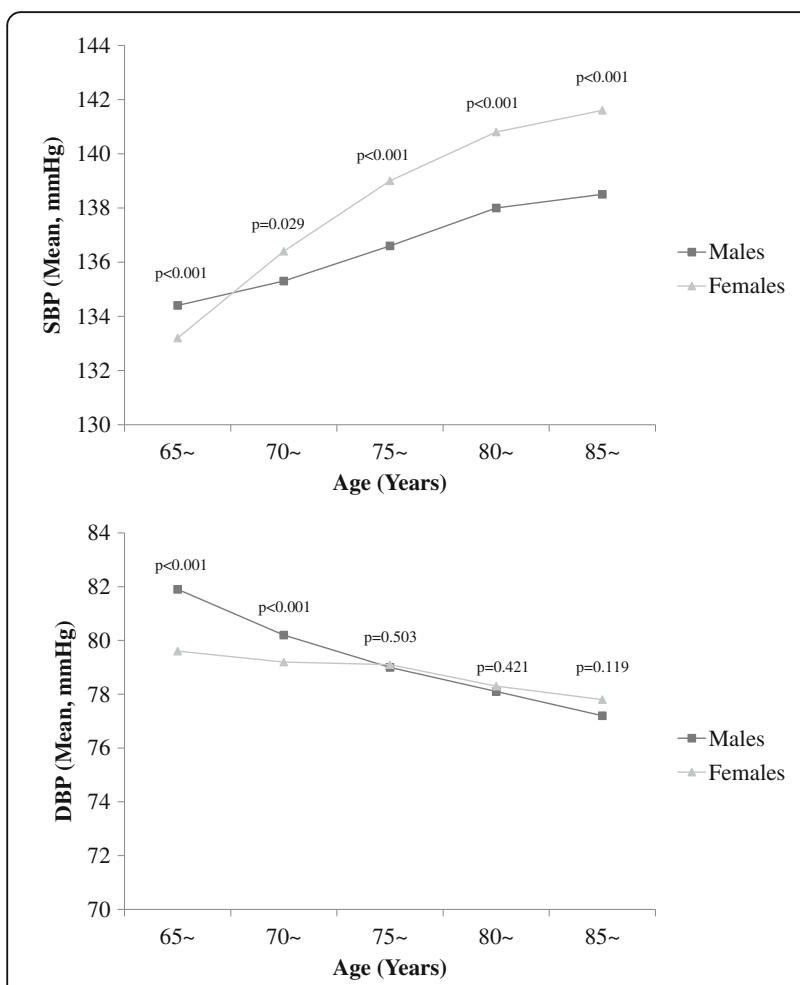

Fig. 1 Mean systolic and diastolic blood pressure by age and sex among all participants. P values represented the differences of SBP or DBP between males and females within different age groups from Mann-Whitney $U$ test due to heteroscedasticity

central Shanghai, which is city in China with the largest number of elderly individuals. Furthermore, because the studied population was composed of a younger population compared to the base population, the disease burden might be underestimated.

This study showed that approximately $60 \%$ of the elderly residents in Changning had hypertension, and this crude prevalence of hypertension increased substantially with age. Meanwhile, the prevalence was higher in elderly females than males, which was a factor that was not observed in previous studies [11]. Hypertension prevalence in the present study was comparable to reports of previous surveys in China [11, 18]. Nonetheless, the prevalence found in this study was slightly lower than the study results from some high-income countries such as the United States [19]. A similar issue was also recognized in hypertension control. According to this study, only one-third of the hypertension patients aged 65 years and older had taken hypertensive medication to provide BP control. The proportion of treatment was much lower compared to other studies in China [10, 20], which might be because Chinese studies usually took the hypertension patients under a specific NCD control program as the denominators when reporting treatment coverage, whereas the denominator for this study was all hypertension patients regardless of their participation in a hypertension management program. The treatment coverage is unsatisfactory compared to high- and upper middle-income countries [11]. Although the proportion of controlled hypertension (43.4\%) in this study was relatively higher compared to other developing countries [11], the control effect of hypertension was still unsatisfactory compared to many developed regions, such as Europe and the United States [21, 22]. Therefore, treatment management for elderly hypertension patients would be a tremendous challenge to the Shanghai health authority and health system.

Old age, being overweight and obesity are traditional risk factors for uncontrolled hypertension [20]. In the meantime, the results of the present study provided additional support for that evidence. A recent study on elderly Chinese individuals aged 80 years or older estimated a hypertension prevalence of $75.3 \%$, while $45.5 \%$ of hypertension was treated, and only $18.1 \%$ of hypertensive participants were controlled [15]. It is revealed that the importance of hypertension prevention and management for China's elderly population would increase sharply with ageing. In the meantime, obesity also provides predictive information on atherosclerotic CVDs [23]. Previous studies indicated that

Table 2 Grades of blood pressure among participants by non-communicable diseases history

\begin{tabular}{|c|c|c|c|c|c|c|c|c|c|c|c|c|c|c|}
\hline \multirow[t]{2}{*}{ Diseases } & \multirow[t]{2}{*}{$\begin{array}{l}\text { Number of } \\
\text { Patients }\end{array}$} & \multirow[t]{2}{*}{$\%$} & \multicolumn{2}{|c|}{$\begin{array}{l}\mathrm{SBP}<120 \\
\mathrm{mmHg} \text { and } \\
\mathrm{DBP}<80 \mathrm{mmHg}\end{array}$} & \multicolumn{2}{|c|}{$\begin{array}{l}\text { SBP:120- } \\
139 \mathrm{mmHg} \\
\text { or DBP:80- } \\
89 \mathrm{mmHg}\end{array}$} & \multicolumn{2}{|c|}{$\begin{array}{l}\text { SBP:140- } \\
159 \text { mmHg } \\
\text { or DBP:90- } \\
99 \text { mmHg }\end{array}$} & \multicolumn{2}{|c|}{$\begin{array}{l}\text { SBP:160- } \\
179 \mathrm{mmHg} \\
\text { or DBP:100- } \\
109 \mathrm{mmHg}\end{array}$} & \multicolumn{2}{|c|}{$\begin{array}{l}\mathrm{SBP} \geq 180 \\
\mathrm{mmHg} \text { or } \\
\mathrm{DBP} \geq 110 \\
\mathrm{mmHg}\end{array}$} & \multicolumn{2}{|c|}{$\begin{array}{l}\mathrm{SBP} \geq 140 \\
\mathrm{mmHg} \text { and } \\
\mathrm{DBP}<90 \\
\mathrm{mmHg}\end{array}$} \\
\hline & & & $n$ & $\%$ & $n$ & $\%$ & $n$ & $\%$ & $n$ & $\%$ & $n$ & $\%$ & $n$ & $\%$ \\
\hline No Confirmed Hypertension & 18,032 & 40.1 & 3627 & 20.1 & 8875 & 49.2 & 4281 & 23.7 & 1035 & 5.7 & 214 & 1.2 & 8641 & 32.1 \\
\hline Hypertension & 26,946 & 59.9 & 1660 & 6.2 & 10,045 & 37.3 & 10,082 & 37.4 & 4027 & 14.9 & 1132 & 4.2 & 3428 & 19.0 \\
\hline Hypertension Only & 13,801 & 30.7 & 842 & 6.1 & 5043 & 36.5 & 5241 & 38.0 & 2144 & 15.5 & 531 & 3.8 & 4230 & 30.6 \\
\hline Hypertension - Diabetes & 6856 & 15.2 & 373 & 5.4 & 2612 & 38.1 & 2521 & 36.8 & 1002 & 14.6 & 348 & 5.1 & 2362 & 34.5 \\
\hline Hypertension - CHD & 6156 & 13.7 & 414 & 6.7 & 2302 & 37.4 & 2252 & 36.6 & 901 & 14.6 & 287 & 4.7 & 2088 & 33.9 \\
\hline Hypertension - Stroke & 2408 & 5.4 & 164 & 6.8 & 936 & 38.9 & 885 & 36.8 & 321 & 13.3 & 102 & 4.2 & 783 & 32.5 \\
\hline All Participants & 44,978 & 100.0 & 5287 & 11.8 & 18,920 & 42.1 & 14,363 & 31.9 & 5062 & 11.3 & 1346 & 3.0 & 12,069 & 26.8 \\
\hline
\end{tabular}




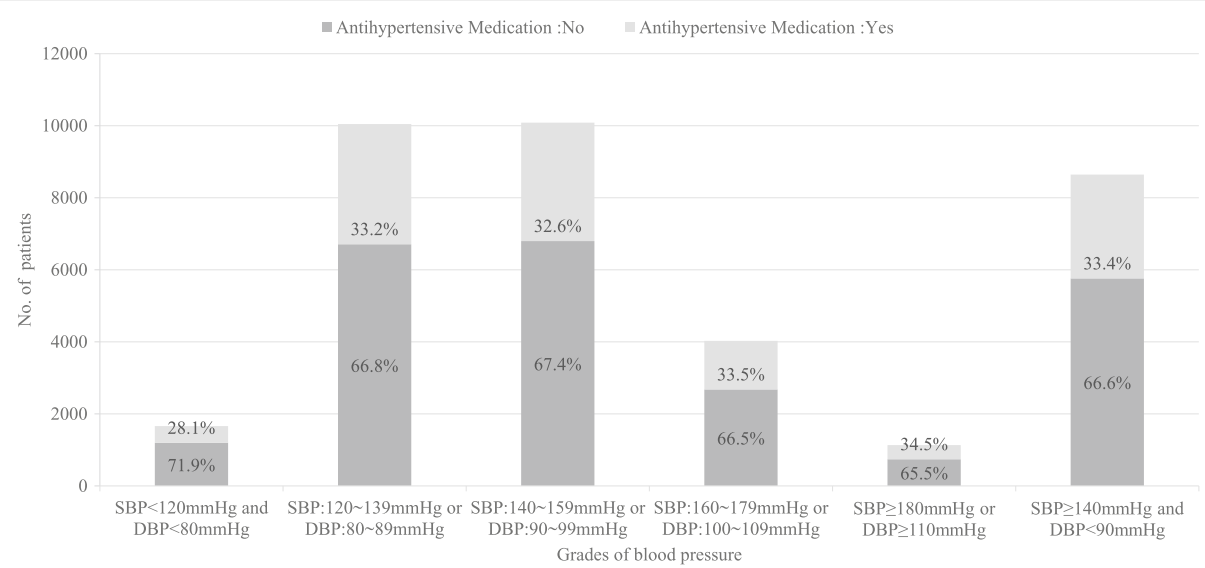

Fig. 2 The proportion of antihypertensive treatment among hypertension patients with different blood pressure grades. The height of each stacked bar showed the absolute number of hypertension patients with the corresponding BP grade. The percentage in the light grey rectangle represented the proportion of those who had taken antihypertensive medication among hypertension patients with the corresponding BP grade; while the percentage in the dark grey rectangle represented the proportion of those who had not taken antihypertensive medication

abdominal obesity and visceral obesity were associated with increased hypertension prevalence among elderly population [15, 24]. Therefore, non-hypertensive elders can prevent hypertension through lifestyle modification and the reinforcement of daily exercise. These methods are also beneficial for the optimal control of BP among elderly patients. As indicated in other reports [25], elderly patients with less education showed less efficient hypertension control. Education is an important tool that leads to a higher socioeconomic status and healthier lifestyle habits, which could both strengthen and improve levels of awareness, treatment and control of hypertension. It has been shown that lack of knowledge hinders medication adherence, especially for an elderly population [26]. Results from multivariate analysis also indicated that the $\mathrm{BP}$ control among males was slightly better than BP control among females, although the difference was not statistically significant. Some studies conducted in other countries, such as Japan, Poland and the United States, reported higher hypertension prevalence and worse BP control among elderly females than elderly males [27-29]. Further populationbased studies are still needed to confirm whether an association exists between sex and BP control among the elderly population. On the other hand, more attention should be given to the effects of BP control among female patients because high blood pressure has a greater impact on cardiovascular risk in females than in males, and females after menopause are especially vulnerable [30, 31].

Previous studies suggested that a balanced diet plays an important role in hypertension prevention and control $[32,33]$. Based on the present study, a dietary pattern with high consumption of meat was associated with uncontrolled hypertension. However, a null association between vegetable consumption and $\mathrm{BP}$ was observed, which was consistent with several other observational studies
$[34,35]$. The Dietary Approaches to Stop Hypertension (DASH) intervention study has shown that a diet rich in fruits, vegetables, and low-fat dairy products as well as low saturated fat can substantially lower both SBP and DBP [36]. Hypertension patients who drank regularly were less likely to have their BP under control. A Korean study discovered the adverse effects of drinking was significant for uncontrolled BP both at nighttime and over 24 h [37]. In fact, heavy drinking itself can be associated with resistant hypertension [38]. In addition, a previous metaanalysis showed that high salt intake was highly prevalent in low- and middle-income countries, and excessive use of salt had a greater impact on hypertension burden in urban regions than rural regions [39]. However, a significant relationship between salt intake and BP control was not observed in this study, which likely occurred due to the generally light cooking style in Shanghai.

Optimal BP control in elderly hypertension patients with comorbidities was achieved with less difficulty than in patients without comorbidities. Similar results were found in the Oslo Health Study 2000-2001 that showed the presence of diabetes or CVD was independently associated with better BP control [40]. In comorbidity situations, diabetes and cardio-cerebral vascular diseases can be aggravated by high or uncontrolled BP. Thus, patients with comorbid conditions are more likely to have frequent hospitalizations and adverse treatment outcomes. Therefore, BP control should be considered the priority for patients with comorbidities, especially for elderly patients. Indeed, there was a null association between antihypertensive treatment and BP control because only one-third of hypertension patients were treated with antihypertensive medication. However, an appropriate combination of antihypertensive medication treatment is still crucial for optimal BP control in both central regions and suburban or rural regions that have 
Table 3 Associations between demographic and life-style factors and uncontrolled BP among elderly hypertension patients in Shanghai

\begin{tabular}{|c|c|c|c|c|c|c|}
\hline \multirow{2}{*}{\multicolumn{2}{|c|}{ Associated factors }} & \multirow[t]{2}{*}{ Total } & \multicolumn{2}{|c|}{$\mathrm{SBP}>140 \mathrm{mmHg}$ or DBP $>90 \mathrm{mmHg}$} & \multirow[t]{2}{*}{$p$} & \multirow[t]{2}{*}{$\mathrm{aOR}(95 \% \mathrm{Cl})^{\mathrm{a}}$} \\
\hline & & & $\mathrm{n}$ & $\%$ & & \\
\hline \multicolumn{3}{|c|}{ Age (Years, Median \& Interquartile range) } & $74(68-79$ & & $<0.001$ & $1.01(1.01-1.02)$ \\
\hline \multirow[t]{2}{*}{ Sex } & Male & 11,936 & 6692 & 56.1 & & Ref. \\
\hline & Female & 15,010 & 8549 & 57.0 & 0.531 & $1.02(0.96-1.08)$ \\
\hline \multirow[t]{4}{*}{$\mathrm{BMI}\left(\mathrm{kg} / \mathrm{m}^{2}\right)$} & $0-$ & 726 & 336 & 46.3 & 0.001 & $0.77(0.65-0.90)$ \\
\hline & $18.5-$ & 10,776 & 5648 & 52.4 & & Ref. \\
\hline & $24.0-$ & 10,864 & 6366 & 58.6 & $<0.001$ & $1.29(1.22-1.37)$ \\
\hline & $28.0-$ & 4080 & 2612 & 64.0 & $<0.001$ & $1.61(1.48-1.74)$ \\
\hline \multirow[t]{5}{*}{ Education } & University & 3699 & 1928 & 52.1 & & Ref. \\
\hline & Senior high school & 6349 & 3516 & 55.4 & 0.003 & $1.14(1.04-1.24)$ \\
\hline & Junior high school & 8794 & 5013 & 57.0 & $<0.001$ & $1.19(1.09-1.29)$ \\
\hline & Primary school & 5242 & 3095 & 59.0 & $<0.001$ & $1.26(1.14-1.38)$ \\
\hline & No formal education & 2443 & 1457 & 59.6 & $<0.001$ & $1.25(1.11-1.41)$ \\
\hline \multirow[t]{3}{*}{ Dietary pattern } & Balanced & 22,559 & 12,690 & 56.3 & & Ref. \\
\hline & Meatarian & 1015 & 627 & 61.8 & 0.003 & $1.23(1.07-1.40)$ \\
\hline & Vegetarian & 3372 & 1924 & 57.1 & 0.210 & $1.05(0.97-1.13)$ \\
\hline \multirow[t]{2}{*}{ Salt intake } & $\leq 6 \mathrm{mg} /$ day & 26,157 & 14,811 & 56.6 & & Ref. \\
\hline & $>6$ mg/day & 789 & 430 & 54.5 & 0.108 & $0.89(0.76-1.03)$ \\
\hline \multirow[t]{3}{*}{ Drinking } & Never & 17,838 & 10,002 & 56.1 & & Ref. \\
\hline & Occasional & 4806 & 2676 & 55.7 & 0.141 & $1.06(0.98-1.13)$ \\
\hline & Regular & 2118 & 1262 & 59.6 & 0.001 & $1.19(1.07-1.31)$ \\
\hline \multirow[t]{2}{*}{ Treatment ${ }^{b}$} & Yes & 8829 & 5027 & 56.9 & & Ref. \\
\hline & No & 18,117 & 10,214 & 56.4 & 0.239 & $0.97(0.92-1.02)$ \\
\hline \multirow[t]{3}{*}{ Comorbidity $^{c}$} & Hypertension only & 14,595 & 8335 & 57.1 & 0.001 & Ref. \\
\hline & 2 NCDs & 9555 & 5346 & 55.9 & 0.002 & $0.91(0.86-0.97)$ \\
\hline & $\geq 3 \mathrm{NCDs}$ & 2796 & 1560 & 55.8 & 0.004 & $0.88(0.80-0.96)$ \\
\hline
\end{tabular}

${ }^{\mathrm{a}}$ Adjusted odds ratio and $95 \%$ confidence interval

${ }^{\mathrm{b}}$ Treatment was defined as taking anti-hypertensive medication

${ }^{c}$ Co-morbidity was defined as having hypertension and $\geq 1$ of the following three diseases: diabetes, coronary heart disease, and stroke

patients with less education and limited qualified medical resources [20].

Nevertheless, this study has limitations. First, it is a secondary analysis of cross-sectional data, so this study could not establish a cause-effect relationship between postulated factors and uncontrolled BP. Second, the study is missing some information, such as the exact date of diagnosis, duration of treatment, and socialeconomic status, such as family income level, that might be associated with hypertension control. Third, participants in this study received the health check-up on a volunteer basis and they might have younger ages and healthier physical conditions than the actual base population [16]. As a result, generalization of these findings from this study to other elderly populations in China should be handled with caution.

\section{Conclusions}

Among elderly residents (aged 65 and above) in central Shanghai, China, the prevalence of hypertension was high, yet the control of hypertension was unsatisfactory. Hypertension control is an essential precondition for reducing the impact, complications and deaths from cardiovascular diseases. This study yielded important information to improve our understanding of the hypertension burden. The study also contributed to clarifying the factors that have hindered hypertension control in this elderly population. Development of strategies that improve the management and control of hypertension among urban elderly residents, especially among hypertension patients without other NCDs are needed to respond to the urgent needs for disease control and comorbidity prevention. 


\section{Abbreviations}

BMl: Body mass index; BP: Blood pressure; CHARLS: China Health and Retirement Longitudinal Study; CHD: Coronary heart disease; CVD: Cardiovascular disease; DASH: Dietary Approaches to Stop Hypertension; DBP: Diastolic blood pressure; JNC-8: The Eighth Joint National Committee; NCDs: Non-communicable diseases; SBP: Systolic blood pressure

\section{Acknowledgements}

The authors thank all study participants, the Shanghai Municipal Commission of Health and Family Planning, Changning District Committee on Ageing, Changning District Health and Family Planning Commission, and the staff of the "Healthy Ageing" Program in the Changning District for their support

\section{Funding}

The secondary data analysis was supported by Shanghai Municipal Commission of Health and Family Planning (2013ZYJB0801) for data analysis, interpretation and publication. Meanwhile, this study was also supported by the Fourth Round of Three-Year Public Health Action Plan of Shanghai, China (15GWZK0101) for discipline (Epidemiology) development in School of Public Health, Fudan University for the work of researchers and graduate students.

\section{Availability of data and materials}

The datasets used during the current study are available from the corresponding author upon reasonable request.

\section{Authors' contributions}

ZY structured the analysis plan, analyzed the data, drafted and revised the article. QZ designed the study, interpreted the data and revised the article. JP and SZ involved in defining variables and developing analysis plan, interpreted data, and drafted the article. BX designed and supervised the whole study, as well as conceptualized, drafted and revised the manuscript. All the authors read and approved the final manuscript, and they ensured the accuracy and integrity of this article.

\section{Ethics approval and consent to participate}

This routine record-based secondary data analysis was approved by the Ethic Committee in Huadong Hospital Affiliated to Fudan University (No. 2014 K004). According to the Ethical Review of Biomedical Research Involving Human Beings [41], which was revised and issued by the National Health and Family Planning Commission in 2016, ethics clearance and informed consent can be exempt if the study just only involves existing data which has been stripped of identification information. There was no individual identification information in the database. All the participants are unable to be contacted, and the objectivity of this study has nothing to do with individual privacy or commercial profits.

\section{Consent for publication}

Not applicable.

\section{Competing interests}

The authors declare that they have no competing interests.

\section{Publisher's Note}

Springer Nature remains neutral with regard to jurisdictional claims in published maps and institutional affiliations.

\section{Author details}

${ }^{1}$ School of Public Health, Fudan University, Shanghai, China. ${ }^{2}$ Key Laboratory of Public Health Safety (Fudan University), Ministry of Education, Shanghai, China. ${ }^{3}$ Changning District Health and Family Planning Commission, Changning District, Shanghai, China. ${ }^{4}$ Huadong Hospital Affiliated to Fudan University, Shanghai, China. ${ }^{5}$ Department of Public Health Sciences (Global Health/IHCAR), Karolinska Institutet, Stockholm, Sweden. ${ }^{6}$ Department of Epidemiology, School of Public Health, Fudan University, No.130 Dong-An Road, Shanghai, China.
Received: 1 April 2017 Accepted: 12 December 2017

Published online: 28 December 2017

\section{References}

1. Mortality GBD. Causes of death collaborators: global, regional, and national age-sex specific all-cause and cause-specific mortality for 240 causes of death, 1990-2013: a systematic analysis for the global burden of disease study 2013. Lancet. 2015;385(9963):117-71.

2. World Health Organization: A global brief on hypertension. Geneva; 2013.

3. Zhao Y, Hu Y, Smith JP, Strauss J, Yang G. Cohort profile: the China health and retirement longitudinal study (CHARLS). Int J Epidemiol. 2014:43(1):61-8.

4. Guo J, CQ Y, Lyu J, Guo Y, Bian Z, Zhou HY, Tan YL, Pei P, Chen JS, Chen $Z M$, et al. Status of prevalence, awareness, treatment and controll on hypertension among adults in 10 regions, China. Zhonghua Liu Xing Bing Xue Za Zhi. 2016:37(4):469-74.

5. Chow CK. Prevalence, awareness, treatment, and control of hypertension in rural and urban communities in high-, middle-, and low-income countries. JAMA. 2013;310(9):959.

6. Zhou M, Wang H, Zhu J, Chen W, Wang L, Liu S, Li Y, Wang L, Liu Y, Yin P, et al. Cause-specific mortality for 240 causes in China during 1990-2013: a systematic subnational analysis for the global burden of disease study 2013 Lancet. 2016:387(10015):251-72.

7. United Nations. World population ageing 2017. New York; 2017.

8. World Health Organization: Global Status Report on Noncommunicable Diseases 2014 Geneva; 2014

9. Wang G, Li LM, YH H, Zhan SY, Lu J, Gao WJ, CO Y, Wang SF, Wang J, Dai $L Q$, et al. Relationship between the clustering of risk factors and the prevalence of hypertension in the community residents living in shanghai. Zhonghua Liu Xing Bing Xue Za Zhi. 2013;34(4):307-10.

10. Sheng CS, Liu M, Kang YY, Wei FF, Zhang L, Li GL, Dong Q, Huang QF, Li Y, Wang JG. Prevalence, awareness, treatment and control of hypertension in elderly Chinese. Hypertens Res. 2013;36(9):824-8.

11. Yang F, Qian D, Hu D. Prevalence, awareness, treatment, and control of hypertension in the older population: results from the multiple national studies on ageing. J Am Soc Hypertens. 2016;10(2):140-8.

12. Li G, Wang H, Wang K, Wang W, Dong F, Qian Y, Gong H, Xu G, Li Y, Pan L, et al. Prevalence, awareness, treatment, control and risk factors related to hypertension among urban adults in Inner Mongolia 2014: differences between Mongolian and Han populations. BMC Public Health. 2016:16:294.

13. Kokubo Y, Ma L, Zhao X, Tang Z, Li Y, Sun F, Diao L, Ge G, Feng M, Wang J. Epidemiological characteristics of hypertension in the elderly in Beijing, China. PLoS One. 2015;10(8):e0135480.

14. Li H, Yan X, Deng X, Yang L, Zhao S, Zou J, Luo Y, Cao S. A cross-sectional study of the prevalence, awareness, treatment and control of hypertension in Shenzhen, China. BMJ Open. 2017;7(6):e015206.

15. Huang G, Jb X, T-j Z, Li Q, X-I N, Liu Y, Peng L Sr, X-t L, X-I K. Prevalence, awareness, treatment, and control of hypertension among very elderly Chinese: results of a community-based study. J American Soc Hypertension. 2017:11(8):503-512.e502.

16. Shanghai Municipal Statistics Bureau, Survey Office of the National Bureau of statistics in shanghai: shanghai statistical yearbook 2015; 2015.

17. James PA, Oparil S, Carter BL, Cushman WC, Dennison-Himmelfarb C, Handler J, Lackland DT, LeFevre ML, MacKenzie TD, Ogedegbe O, et al. 2014 evidence-based guideline for the management of high blood pressure in adults: report from the panel members appointed to the eighth joint National Committee (JNC 8). JAMA. 2014;311(5):507-20

18. Lloyd-Sherlock P, Beard J, Minicuci N, Ebrahim S, Chatterii S. Hypertension among older adults in low- and middle-income countries: prevalence, awareness and control. Int J Epidemiol. 2014:43(1):116-28.

19. Ostchega Y, Dillon CF, Hughes JP, Carroll M, Yoon S. Trends in hypertension prevalence, awareness, treatment, and control in older U.S. adults: data from the National Health and nutrition examination survey 1988 to 2004. J Am Geriatr Soc. 2007:55(7):1056-65.

20. Yang L, Xu X, Yan J, Yu W, Tang X, Wu H, Parkin CL. Analysis on associated factors of uncontrolled hypertension among elderly hypertensive patients in southern China: a community-based, cross-sectional survey. BMC Public Health. 2014;14:903.

21. Borghi C, Tubach F, De Backer G, Dallongeville J, Guallar E, Medina J, Perk J Roy C, Banegas JR, Rodriguez-Artalejo F, et al. Lack of control of hypertension in primary cardiovascular disease prevention in Europe: results from the EURIKA study. Int J Cardiol. 2016;218:83-8. 
22. Guo F, He D, Zhang W, Walton RG. Trends in prevalence, awareness, management, and control of hypertension among United States adults, 1999 to 2010. J Am Coll Cardiol. 2012;60(7):599-606.

23. Fan H, Li X, Zheng L, Chen X, Lan Q, Wu H, Ding X, Qian D, Shen Y, Yu Z, et al. Abdominal obesity is strongly associated with cardiovascular disease and its risk factors in elderly and very elderly community-dwelling Chinese. Sci Rep. 2016;6:21521.

24. Rahmouni K, Correia ML, Haynes WG, Mark AL. Obesity-associated hypertension: new insights into mechanisms. Hypertension. 2005;45(1):9-14.

25. Chor D, Pinho RA, Sa CM, Duncan BB, Andrade LP, Araujo NA, Aquino EM, Schmidt MI, Griep RH, Molina MC, et al. Prevalence, awareness, treatment and influence of socioeconomic variables on control of high blood pressure: results of the ELSA-Brasil study. PLoS One. 2015;10(6):e0127382.

26. Turner BJ, Hollenbeak C, Weiner MG, Ten Have T, Roberts C. Barriers to adherence and hypertension control in a racially diverse representative sample of elderly primary care patients. Pharmacoepidemiol Drug Saf. 2009; 18(8):672-81.

27. Zdrojewski T, Wizner B, Wiecek A, Slusarczyk P, Chudek J, Mossakowska M, Bandosz P, Bobak M, Kozakiewicz K, Broda G et al: Prevalence, awareness, and control of hypertension in elderly and very elderly in Poland: results of a cross-sectional representative survey. J Hypertens 2016, 34(3):532-538; discussion 538.

28. Lloyd-Jones DM, Evans JC, Levy D. Hypertension in adults across the age spectrum: current outcomes and control in the community. JAMA. 2005; 294(4):466-72.

29. Ishine M, Okumiya K, Hirosaki M, Sakamoto R, Fujisawa M, Hotta N, Otsuka K, Nishinaga M, Doi Y, Matsubayashi K. Prevalence of hypertension and its awareness, treatment, and satisfactory control through treatment in elderly Japanese. J Am Geriatr Soc. 2008;56(2):374-5.

30. Gu Q, Burt VL, Paulose-Ram R, Dillon CF. Gender differences in hypertension treatment, drug utilization patterns, and blood pressure control among US adults with hypertension: data from the National Health and nutrition examination survey 1999-2004. Am J Hypertens. 2008;21(7):789-98.

31. Vitale C, Miceli M, Rosano GM. Gender-specific characteristics of atherosclerosis in menopausal women: risk factors, clinical course and strategies for prevention. Climacteric. 2007;10(Suppl 2):16-20.

32. Lee SA, Cai H, Yang G, WH X, Zheng W, Li H, Gao YT, Xiang YB, Shu XO. Dietary patterns and blood pressure among middle-aged and elderly Chinese men in shanghai. Br J Nutr. 2010;104(2):265-75.

33. Miura K, Greenland P, Stamler J, Liu K, Daviglus ML, Nakagawa H. Relation of vegetable, fruit, and meat intake to 7-year blood pressure change in middle-aged men: the Chicago western electric study. Am J Epidemiol. 2004;159(6):572-80.

34. Sadakane A, Tsutsumi A, Gotoh T, Ishikawa S, Ojima T, Kario K, Nakamura Y, Kayaba K. Dietary patterns and levels of blood pressure and serum lipids in a Japanese population. J Epidemiol. 2008;18(2):58-67.

35. Chen $Y$, Factor-Litvak P, Howe GR, Parvez F, Ahsan H. Nutritional influence on risk of high blood pressure in Bangladesh: a population-based crosssectional study. Am J Clin Nutr. 2006;84(5):1224-32.

36. Appel LJ, Moore TJ, Obarzanek E, Vollmer WM, Svetkey LP, Sacks FM, Bray GA, Vogt TM, Cutler JA, Windhauser MM, et al. A clinical trial of the effects of dietary patterns on blood pressure. DASH collaborative research group. $\mathrm{N}$ Engl J Med. 1997;336(16):1117-24.

37. Choi SI, Kim SK, Park S, Kim JH, Ihm SH, Kim Gl, Kim WS, Pyun WB, Kim YM, Shin J. Prevalence of resistant hypertension and associated factors for blood pressure control status with optimal medical therapy using Korean ambulatory blood pressure monitoring registry data. Clin Hypertens. 2015;22(1):8.

38. Fan HQ, Li Y, Thijs L, Hansen TW, Boggia J, Kikuya M, Bjorklund-Bodegard K, Richart T, Ohkubo T, Jeppesen J, et al. Prognostic value of isolated nocturnal hypertension on ambulatory measurement in 8711 individuals from 10 populations. J Hypertens. 2010;28(10):2036-45.

39. Subasinghe AK, Arabshahi S, Busingye D, Evans RG, Walker KZ, Riddell MA, Thrift AG. Association between salt and hypertension in rural and urban populations of low to middle income countries: a systematic review and metaanalysis of population based studies. Asia Pac J Clin Nutr. 2016;25(2):402-13.

40. Tonstad S, Furu K, Rosvold EO, Skurtveit S. Determinants of control of high blood pressure. The Oslo health study 2000-2001. Blood Press. 2004;13(6):343-9.

41. Ethical Review of Biomedical Research Involving Human Beings [http://www. moh.gov.cn/fzs/s3576/201610/84b33b81d8e747eaaf048f68b 174f829.shtml].

\section{Submit your next manuscript to BioMed Central and we will help you at every step:}

- We accept pre-submission inquiries

- Our selector tool helps you to find the most relevant journal

- We provide round the clock customer support

- Convenient online submission

- Thorough peer review

- Inclusion in PubMed and all major indexing services

- Maximum visibility for your research

Submit your manuscript at www.biomedcentral.com/submit
Biomed Central 